\title{
Zhuanggu Guanjie herbal formula mitigates osteoarthritis via NF-kB transduction mechanism in vitro
}

\section{Guowei Gong}

Zunyi Medical University - Zhuhai Campus

\section{Yuzhong Zheng ( $\nabla$ zhengyuzhong@gmail.com )}

Hanshan Normal University https://orcid.org/0000-0001-7208-0642

\section{Xuan Zhou}

Zunyi Medical University - Zhuhai Campus

\section{Zhi Dai}

China Resources Sanjiu Medical and Pharameutical company Water Resources

\section{Juanhui Duan}

China Resources Sanjiu Medical and Pharmaceutical company

\section{Peikui Yang}

Chaozhou peoples' Hospital

\section{Xiangzhi Liu}

Chaozhou peoples' hospital

\section{Zhen Wen}

Shenzhen University

\section{Research}

Keywords: Zhuanggu Guanjie capsules, anti-osteoarthritis, inflammation

Posted Date: September 2nd, 2021

DOI: https://doi.org/10.21203/rs.3.rs-839229/v1

License: (1) (1) This work is licensed under a Creative Commons Attribution 4.0 International License. Read Full License 


\section{Abstract}

\section{Background}

Zhuanggu Guanjie herbal formula, a famous Chinese prescription, which is commonly applied for mitigating bone-related problems, clinically. According to the China Pharmacopeia (CP, 2020), this herbal formula includes 12 raw materials, and the major components are Rehmanniae Radix (RR) and Psoraleae Fructus (PF). The anti-osteoarthritis properties of this herbal prescription are well-documented in CP (2020). However, the working mechanism of this ancient herbal formula has not been elucidated. Therefore, we would like to probe the anti-osteoarthritis pharmaceutical values of this ancient herbal prescription.

Materials and methods

The differentiated ATDC5 cells were employed in the following experiments. In the present study, the involvements of cytokine levels and hallmark proteins reflecting inflammatory responses in Zhuanggu Guanjie Capsule (ZGC)-induced differentiated cells were detected by RT-PCR, flow cytometer, western blot and laser confocal assays.

Results

The cytokines and inflammation-specific proteins, i.e. interleukin (IL)-6, tumor necrosis factor- (TNF-) and inducible nitric oxide synthase (iNOS), cyclooxygenase-2 (COX-2) and prostaglandin synthesis E2 (PGES2) were robustly declined after incubating with ZGC for 48 hours, and the attenuation levels were in a dose-dependent manner. Furthermore, ZGC could also block NF-B translocation from cytosol to nucleus and which has been verified by the laser confocal microscope.

\section{Conclusions}

The in vitro studies have clarified the anti-osteoarthritis properties of ZGC and the working mechanism involved, and this herbal formula shed light on osteoarthritis treatment.

\section{Introduction}

Osteoarthritis is classified as musculoskeletal degenerative diseases, and which frequently involving chronic pain and joint dysfunctions [1, 2]. Chronic inflammatory responses of the synovial membrane and progressive destruction of the articular cartilage are the indicators of this disease [3]. Cartilage damage triggers synovial inflammation, and chondrocyte-mediated inflammatory responses as a critical factor in the development of osteoarthritis [4]. In fact, pathogenesis of osteoarthritis is still behind veil, myriad studies have documented that inflammatory responses are the key factor for the development of this joint degenerative illness [5]. Therefore, mitigating chondrocyte inflammation plays a important function in reversing or altering the progression of osteoarthritis. The standard treatment for osteoarthritis is applying steroid [6]. However, long term treatment triggers other bone diseases, i.e. osteoporosis, joint 
deformity and etc [1, 2]. Therefore, people would like to approach traditional Chinese medicine (TCM) to alleviate osteoarthritis and in order to improve life quality.

In TCM filed, osteoarthritis commonly classified as Arthralgia Syndrome, which originated from the ancient book "Huangdi Neijing". Previous studies have documented that TCM mainly via antiinflammatory and anti-osteoporosis mechanisms to conduct anti-osteoarthritis functions [7]. Rehmanniae Radix (RR) and Psoraleae Fructus (PF) are the most commonly utilized Materia Medica to strength kidney and enhance bone, which were firstly recorded in Chinese herbal medicine book, called "Shennong Bencao Jing" [8, 9]. Chen et al. (2014) have elucidated that RR is the most commonly used herbal medicine for musculoskeletal degenerative diseases treatment [10]. Jhun et al. (2018) published RR extract mitigate cartilage degeneration by suppressing metalloproteinase 3 and nitrotyrosine in osteoarthritis rat model joints [11]. Siu et al. (2019) reported that PF extract suppressed inflammatory mediator releases via PI3K/Akt pathway to play the anti-osteoarthritis properties in vitro [12]. Oral administration of PF water extract for 14 days on osteoarthritis rat model, the productions of interleukin (IL)-6, tumor necrosis factor-a (TNF-a) and inducible nitric oxide synthase (iNOS) were decreased dramatically in plasma as compared with sham group [12].

Multitude transduction pathways have been elucidated to act the indispensable functions in monitoring the progression of osteoarthritis. Nuclear factor kappa-light-chain-enhancer of activated B cells (NF-kB) transduction mechanism is widely distributed in various type of cells, modulating immune-related responses $[13,14]$. Under the normal condition, NF-KB interact with inhibitory kappa-B a $(\mathrm{IKBa})$ in the cytosol [15]. І $\mathrm{KBa}$ is the specific inhibitory protein of NF-KB [15]. Once receiving stimulus, IKB kinase is activated by phosphorylating IKB protein, and then stimulating NF-KB translocates from cytosol to nucleus and triggering the target gene expressions, i.e. IL-1 $\beta$, IL-6, TNF-a, iNOS, cyclooxygenase-2 (COX-2) and prostaglandin synthesis E2 (PGES-2) [14]. The production of cytokines or inflammatory mediators significantly accelerate the degradation development of extracellular matrix, which further aggravates the progression of osteoarthritis $[16,17]$.

Zhuanggu Guanjie Capsule (ZGC) contains 12 Materia Medica, and RR and PF are the predominant herbs found within this formula. This herbal formula has been written in China pharmacopoeia (CP, 2020) as the medicinal treatment for osteoarthritis patients [18]. But, the detailed pharmacological mechanisms of ZGC with osteoarthritis-related targets and pathways need to be probe. In the current study, we would like to probe the transcriptional activity of this herbal formula in cultured ATDC5 cells.

\section{Methods And Materials}

\section{ZGC extract preparation}

ZGC was purchased from China Resources Sanjiu Medical \& Pharmaceutical Co., Ltd, the catalog number was 1912002S. The mixture was resolved in water by sonication [19]. The extracts were dried by lyophilization and stored at $-80^{\circ} \mathrm{C}$ at the final concentration at $100 \mathrm{mg} / \mathrm{mL}$. 


\section{Cell culture}

ATDC5 cell was purchased and shipped from American Type Culture Collection (ATCC, Manassas, VA) and growth in DMEM/F12 medium containing $100 \mathrm{IU} / \mathrm{mL}$ penicillin, $100 \mu \mathrm{g} / \mathrm{mL}$ streptomycin and $10 \%$ fetal bovine serum. ATDC5 were incubated at $37{ }^{\circ} \mathrm{C}$ incubator with $5 \% \mathrm{CO}_{2}$. Once the cells were $70 \%$ confluent, the medium was supplemented with $1 \%$ ITS and to induce chondrocyte-like cells. Chondrocytelike cells were pre-treatment with Lipopolysaccharide (LPS, $1 \mu \mathrm{g} / \mathrm{mL})$ for 24 hours before drug or herbal extract presence. LPS was obtained from Sigma (St. Louis, MO).

\section{Pl-Annix staining assay}

Cells were seeded in 35-mm culture plates and allowed to grow for 24 hours in medium before drug treatment. The Annexin V-FITC/PI Detection kit was employed using flow cytometry (BD Biosciences, Franklin Lakes, NJ). Briefly, cells were washed by PBS twice and then harvested. Cells were incubated in $100 \mu \mathrm{L}$ of binding buffer, containing Annexin-V/FITC and propidium iodide (PI), for 15 min at room temperature and kept in dark. The samples were automatically acquired using the loader with acquisition criteria of 10,000 events for each tube, and the quadrants were set according to the population of viable. The results were analyzed using the FlowJo v10.6 software.

\section{Real time PCR}

The transcriptional levels of IL-1 $\beta$, IL- 6 and TNF- $a$ were detected in LPS-stimulated chondrocyte-like cells. After the ZGC treatment for 48 hours, total RNA was isolated by RNAzol reagent (Molecular Research Center, Cincinnati, $\mathrm{OH}$ ) and then reversed transcribed into cDNAs by using M-MLV (moloneymurine leukemia virus) reverse transcriptase according to the manufacturer's suggestions (Sigma). Real-time PCR was employed here by using FastStart Universal SYBRGreen Master (ROX) according to the manufacturer's instructions (Roche Applied Science, Mannheim, Germany). The sequences of primers were shown here: 5'-AAA TAC CTG TGG CCT TG-3' (sense primer, S) and 5'-TTA GGA AGA CAC GGA TTC3' (antisense primer, AS) for murine IL-1 $\beta$ (NM_008361); 5'-GGA GTA CCA TAG CTACCT GG-3' (S) and 5'CTA GGT TTG CCG AGT AGA TC-3' (AS) for murine IL-6 (NM_031168); 5'- AGT GAC AAG CCT GTA GCC -3' (S) and 5'-AGG TTG ACT TTC TCC TGG-3' (AS) for murine TNF-a (NM_013693); 5'-GAT GAG GCT GCG GAA GAA GG-3' (S) and 5'-GCG AAG GCG TGG GTT CAG-3' (NM_022415). Glyceraldehyde 3-phosphate de-hydrogenase (GAPDH) was used as an internal control, and the sequences were shown here: 5'-AAC GGA TTT GGC CGT ATT GG-3' (S) and 5'- CTT CCC GTT CAG CTC TGG G-3'(AS) (NR_0215885). SYBR green signal was revealed by ABI 7500 Fast Real-Time PCR system (Applied Biosystems, Foster City, CA). Transcript levels were quantified by using $\Delta C t$ value method $[14,20]$, where the values of target genes were normalized by GAPDH in the same sample. Dexamethasone (Dex, $10 \mu \mathrm{M})$ was obtained from Sigma working as positive control in all experiments.

\section{Protein expression of cytokines}


Protein expressions of proinflammatory cytokines after drug treatment for 2 days were revealed by Milliplex ${ }^{\circledR}$ technology (Millipore, MA). Supernatants of culture medium were collected to measure the concentrations of cytokines (IL-1 $\beta$, IL- 6 and TNFa) using Milliplex® technology, followed the manufacturer's instruction.

\section{ROS formation}

Fluorometric measurements of reactive oxygen species (ROS) were utilized CellROX Deep Red Fluorescence Flow Cytomer detection kit (BD Biosciences) under manufacturer's suggested protocol. Briefly, cells at were incubated in $100 \mu \mathrm{L}$ of binding buffer for $15 \mathrm{~min}$ at room temperature. Samples were automatically acquired using the loader with acquisition criteria of 10,000 events for each tube, and the quadrants were set according to population of viable. The cytometer results were analyzed with Flowjo v7.6 software.

\section{Western blot}

Cell lysate were subjected to SDS-PAGE in revealing protein expressional levels of target genes. After transferring the target proteins to membranes, the membranes were incubated with anti-iNOS (CST, Danvers, MA) at 1:5,000 dilutions, anti-COX-2 (CST) at $1: 5,000$ dilutions, anti-PGES2 (Santa Cruz, Dallas, TX) at 1:5000 dilutions and anti-GAPDH (Santa Cruz) at $1: 5,000,000$ dilutions at $4{ }^{\circ} \mathrm{C}$ for overnight. Following incubation in horseradish peroxidase (HRP)-conjugated secondary antibodies for 3 hours at room temperature, the immune-complexes were visualized by the enhanced chemiluminesence (ECL) method (Amersham Biosciences, Piscataway, NJ). The band intensities were calculated and analyzed by Image $J$.

\section{Laser confocal assay}

The translocation of NF-KB p65 subunit was activated by treatment of $1 \mu \mathrm{g} / \mathrm{mL}$ of LPS for 24 hours and then presence with ZGC for another 48 hours. Then, cells were fixed for $10 \mathrm{~min}$ in $4 \%$ methanol-free paraformaldehyde. Antibodies were diluted in PBS containing $2.5 \%$ fetal bovine serum, and $0.1 \%$ Triton X-100 (Sigma). NF-KB p65 subunit antibody was diluted 1:500 in PBS. Samples were incubated for overnight at cold room. Then, 1:1,000 dilution of secondary FITC-conjugated $F\left(a b^{\prime}\right) 2$ fragment donkey anti-rabbit IgG antibody (Jackson Laboratories, West Grove, PA) was added, incubated at room temp for 3 hours, in dark. After incubating, the cells were washed for 3 times by PBS. Before performing assay, 1: 5,000 dilution of DAPI was added to stain nucleus. Fluorimetric measurements were performed using an Olympus Fluoview FV1000 laser scanning confocal system (Olympus America, Melville, NY) mounted on an inverted Olympus microscope, equipped with a $63 \mathrm{X}$ objective.

\section{Statistical analysis and other assays}

Protein concentrations were measured by Bradford's method (Herculues, CA). Statistical tests have been done by using one-way analysis of variance. Data were expressed as Mean \pm SEM, where $n=3-4$. Statistically significant changes were classified as significant $\left(^{*}\right)$ where $p<0.05$, more significant $(* *)$ 
where $p<0.01$ and highly significant $(* \star *)$ where $p<0.001$ as compared with control group. Significant $\left({ }^{\wedge}\right)$ where $p<0.05$, more significant $\left({ }^{\wedge \wedge}\right)$ where $p<0.01$ and highly significant $\left({ }^{\wedge \wedge \wedge}\right)$ where $p<0.001$ are compared with positive control group.

\section{Results}

The potential strategies for cartilage tissue regeneration by induction of chondrogenesis is the most important treatment for osteoarthritis [21]. The chondrogenic ATDC5 cell line is derived from mouse teratocarcinoma cells and enters a sequential differentiation process analogous to that in chondrocytes and therefore, the differentiated ATDC5 cells is the most commonly utilized in vitro model for cell behavior studies during chondrogenesis [22,23]. Differentiated ATDC5 cells viability serves as one of the key parameters reflecting osteoarthritis process [21]. Here, we utilized LPS to stimulate the activation of differentiated ATDC5 cells for mimicking inflammatory conditions in vitro. The inhibition of cell apoptosis was analyzed in LPS-induced cultured cells in the presence or absence of this herbal formula (Fig. 1). Annexin V-FITC- and PI-labeled cells were subjected to flow cytometry (Fig. 1). ATDC5 cell viability was dramatically altered in the presence of LPS at $1 \mu \mathrm{g} / \mathrm{mL}$ (Fig. 1). Interestingly, we found this herbal formula restricted cell apoptosis rate as compared to the inflammatory condition group (Fig. 1).

The pro-inflammatory cytokines, i.e. IL-1 $1 \beta$, IL- 6 and TNF-a could establish an environment of activating inflammation, which are believed to promote osteoarthritis progression [5, 7]. The LPS-induced up regulation of the mRNAs encoding IL-1 $\beta$, IL- 6 and TNF- $\alpha$ were suppressed, revealed by PCR, by ZGC extract in a dose-dependent manner (Fig. 2). The highest suppression was revealed to be at $0.5 \mathrm{mg} / \mathrm{mL}$ of the extract, and which showed $~ 42 \%$ for IL-1 $\beta, ~ 57 \%$ for IL- 6 and 73\% for TNF-a, respectively (Fig. 2). Dex was applied as positive control, and which suppressed cytokine expression dramatically as shown in Fig. 2. The LPS could trigger the inflammatory status in chondrocyte-like cells and the cytokine production levels were robustly stimulated (Fig. 3). The protein levels of these pro-inflammatory cytokines were also mitigated after ZGC presence over 2 days (Fig. 3). The alleviation properties of ZGC were in a dose-dependent manner, and the maximal concentration was achieved at $0.5 \mathrm{mg} / \mathrm{mL}$ (Fig. 3).

Studies have shown that oxidants can cause oxidative stress in cells, produce numerous ROS, and then activate tyrosine protein kinases [3]. ROS is involved in protein tyrosine phosphorylation and regulates cell proliferation, differentiation, growth, metabolism, survival and etc. Furthermore, ROS initiates IKB kinase and triggers IKB phosphorylation, and finally mediates cell death $[1,2]$. The free NF-kB heterodimer released from IKB and translocates from cytosol to nucleus and then binds with the kappa region of the genome. Kappa region gene transcription increases the production of inflammatory cytokines such as TNF-a, IL-6, COX-2, and iNOS, and which have been reported to be committed in inflammation and osteoarthritis [1, 2]. We revealed the contents of these mediators in LPS-stimulated chondrocyte-like cells. The concentration of ROS was triggered robustly in LPS mimicking group as compared to the control group (Fig. 4). The incubation with ZGC was able to attenuate LPS-induced ROS formation and generation, significantly (Fig. 4). Here, Dex was served as positive control which frequently applied in the clinical treatment (Fig. 4). The translational properties of LPS-induced COX-2, iNOS and PGES-2 were 
decreased under the application of various concentrations of ZGC extract, as compared to the control (Fig. 5). These suppression functions were in a dose-dependent manner after 48 hours incubation with ZGC but with a statically differences (Fig. 5). The minimal inhibition level was revealed at $0.125 \mathrm{mg} / \mathrm{mL}$ of ZGC formula extract, and which could decrease the iNOS, COX-2 and PGES-2 expression at different contents (Fig. 5). The maximal suppression was with the present of $0.5 \mathrm{mg} / \mathrm{mL}$ ZGC formula extract (Fig. 5).

Once NF-kB being activated, i.e. in the inflammatory situation, the protein is translocated into nucleus as to regulate the transcription of inflammatory mediators [3]. In cultured chondrocyte-like cells, LPS provoked NF-KB translocation from cytosol to nuclei as reflected by fluorescence co-localization data (Fig. 6). The translocation functions of this transcriptional factor were attenuated after ZGC presence as shown in Fig. 6. Dex restrained the NF-KB translocation from cytosol to nuclei robustly after 48 hours application (Fig. 6).

\section{Discussion}

TCM has a broad range of materials, and which are frequently applied under the TCM principle for the prevention, diagnosis and treatment of disease, furthermore, which could also regulate capacity of human body. TCM contains herbs, animal drugs, shellfishes, minerals, magnets and etc [24]. There are over 600 types of Chinese herbs are included in CP (2020). Amongst all the TCM, herbal medicine accounts for the majority, and which are commonly consumed in our daily life. TCM can be clustered in several types according to the "four natures" theory, and they are namely hot, warm, cold, neutral and aromatic. In addition, TCM also enjoys "five flavors", and they are sour, bitter, sweet, spicy and salty, respectively [25]. Each herb experiences its unique nature and flavor, which account the herbal properties which influencing the yin-yang of body, as well as the prevention and treatment of the diseases [26].

According to the compatibility of TCM, the role of each herb in formula can be described as "Master, Minister, Assistant and Servant". In brief, "Master" herbs aim to the main syndrome of a disease. "Minister" herbs help to improve the therapeutic effect and reduce the toxicity of the "Master" herbs. "Assistant" herbs cooperate with "Master" and "Minister" herbs to enhance the therapeutic effects or to reverse the accompanying syndromes. "Servant" herbs regulate the properties of other herbs in herbal mixture. The compatibility of herbs is usually modified in terms of syndrome differentiation [27, 28]. In TCM, the herbal mixture is often prepared by water under moderate heating, which is considered as a common and widely used method in clinical application. The extraction method possesses the benefits of being prepared and administrated easily [29]. However, the disadvantages are the large amount of volume, difficulties in quality control and storage. Herbal formula is commonly used as pill, or grounded powder, for easy carry and storage.

Cytokines and ROS play important roles in accelerating the osteoarthritis development, and which stimulating bone cell damage and/or apoptosis, joint synovial inflammation, affecting chondrocyte anabolism, leading to cartilage degradation $[30,31]$. Among the inflammatory cytokines, especially IL-1 $\beta$, 
IL-6, are confirmed to act as the indispensible roles in modulating osteoarthritis pathological process [32]. These cytokines up-regulate immune-specific mediator productions, i.e. iNOS, COX-2 and PGES-2. TNF-a is one of another important cytokines that drives the pathogenesis and progression of osteoarthritis [33]. TNF-a stimulates matrix metalloproteinase (MMP) and 'aggrecanase' a disintegrin and metalloproteinase with thrombospondin motifs (ADAMTSs) expressions [32,34]. ROS acts as second messenger to activate NF-KB transduction pathway, which in turn leads to a cascade of inflammatory mediator factors production [33]. These factors activate immature osteoclasts to erode bone, interfering with chondrocyte metabolism and promoting cartilage degradation to produce irreversible fibrosis, thereby aggravating osteoarthritis $[33,34]$. Therefore, mitigation of cytokineand ROS productions are the effective treatment for osteoarthritis.

RR and PF were documented in "Shennong Bencao Jing", and which were widely used in the boosting kidney function and mitigating bone-related diseases [24]. Flavonoids are the active ingredient extracted from these two Materia Medica, and they are the multi-functional phytochemical presenting substantial characteristics that can be exploited for therapeutic agents targeting on various diseases, pharmaceutically [35]. Xiao et al. (2021) found that flavonoid-enriched RR extract shown the neuronal protective properties by suppressing of the NF-KB and MAPK signaling pathway [36]. Xie and Du (2011) published the similar results, they found RR methanol extraction shown the therapeutic functions for inflammatory treatment by blocking TNF-a, IL-1 $\beta$, IL- 6 and IL-15 productions [37]. Jin et al. (2014) reported that oral administration of PF significantly reduced airway hyperresponsiveness to aerosolized methacholine and decreased IL-4 and IL-13 levels in the Bronchoalveolar lavage fluid [38]. The in vitro studies have implied that alcoholic extract of PF suppressed Th2 cytokines of IL-4, IL-5 and IL-13 by ConA-stimulated D10 cells without inhibitory effect on cell viability [38].

\section{Conclusion}

From our preliminary results, we found ZGC were capable of attenuating IL-1 $1 \beta$, IL- 6 and TNF- $a$ productions via NF-KB working mechanism. Therefore, ZGC might shed light on osteoarthritis treatment, however, the animal studies are still need to further verify the in vivo pharmaceutical properties of this traditional herbal formula.

\section{Abbreviations}

ADAMTSs: 'Aggrecanase' a disintegrin and metalloproteinase with thrombospondin motifs; COX-2: Cyclooxygenase-2; CP: China Pharmacopeia; ECL: Enhanced chemiluminesence; HRP: Horseradish peroxidase; IKB: Inhibitory kappa-B; IL: Interleukin; iNOS: Inducible nitric oxide synthase; LPS:

Lipopolysaccharide; MMP: Matrix metalloproteinase; NF-kB: Nuclear factor kappa-light-chain-enhancer of activated B cells; PF: Psoraleae Fructus; PGES-2: Prostaglandin synthesis E2; ROS: Reactive oxygen species; RR: Rehmanniae Radix; TCM: Traditional Chinese medicine; TNF-a: Tumor necrosis factor-a; ZGC: Zhuanggu Guanjie capsule. 


\section{Declarations}

Ethics approval and consent to participate

Not applicable

Consent for publication

Not applicable

Availability of data and materials

Not applicable

Competing interests

The authors declare that they have no competing interests

\section{Funding sources}

Supported by Guizhou Provincial Natural Science Foundation (QKH-J [2020] 1Y377), Zunyi Science and Technology Project [ZSKHHZZ(2020)85], Science and Technology Program of Guizhou Province (QKPTRC[2019]-024), Zunyi Medical University for the Doctoral Program (F-937), Guangdong Key Laboratory for Functional Substances in Medicinal Edible Resources and Healthcare Products (2021B1212040015), Science and Technology Program of Guangdong Province (2018A030307074), National Natural Science Foundation of China (82160825 and 22078198).

\section{Conflict of Interest}

The author(s) declare(s) that there is no conflict of interests regarding the publication of this paper.

\section{Authors contributors}

Guowei Gong performed the experiments. Guowei Gong and Yuzhong Zheng were responsible for drafting the manuscript. Zhi Dai and Juanhui Duan was responsible for purchasing consumables, preparing reagents and providing raw materials. Xuan Zhou, Peikui Yang, Xiangzhi Liu and Zhen Wen were responsible for data analyze and polishing manuscript.

\section{Acknowledgements}

Not applicable

\section{References}


1. Felson DT, Lawrence RC, Dieppe PA, Hirsch R, Helmick CG, Jordan JM, Kington RS, Lane NE, Nevitt MC, Zhang Y, Sowers M, McAlindon T, Spector TD, Poole AR, Yanovski SZ, Ateshian G, Sharma L, Buckwalter JA, Brandt KD, Fries JF. Osteoarthritis: new insights. Part 1: the disease and its risk factors. Ann Intern Med. 2000;133:635-46.

2. Felson DT, Lawrence RC, Hochberg MC, McAlindon T, Dieppe PA, Minor MA, Blair SN, Berman BM, Fries JF, Weinberger M, Lorig KR, Jacobs JJ, Goldberg V. Osteoarthritis: new insights. Part 2: treatment approaches. Ann Intern Med. 2000;133:726-37.

3. Woodell-May JE, Sommerfeld SD. Role of inflammation and the immune system in the progression of osteoarthritis. J Orthop Res. 2020;38:253-7.

4. Scanzello CR. Role of low-grade inflammation in osteoarthritis. Curr Opin Rheumatol. 2017;29:7985.

5. Sokolove J, Lepus CM. Role of inflammation in the pathogenesis of osteoarthritis: latest findings and interpretations. Ther Adv Musculoskelet Dis. 2013;5:77-94.

6. de Lange-Brokaar BJ, loan-Facsinay A, van Osch GJ, Zuurmond AM, Schoones J, Toes RE, Huizinga TW, Kloppenburg M. Synovial inflammation, immune cells and their cytokines in osteoarthritis: a review. Osteoarthritis Cartilage. 2012;20:1484-99.

7. Yang M, Jiang L, Wang Q, Chen H, Xu G. Traditional Chinese medicine for knee osteoarthritis: an overview of systematic review. PLoS One. 2017;12:e0189884.

8. Gong W, Zhang N, Cheng G, Zhang Q, He Y, Shen Y, Zhang Q, Zhu B, Zhang Q, Qin L. Rehmannia glutinosa Libosch extracts prevent bone loss and architectural deterioration and enhance osteoblastic bone formation by regulating the IGF-1/PI3K/mTOR pathway in streptozotocin-induced diabetic rats. Int J Mol Sci. 2019;20:3964.

9. Ota M, Nakazaki J, Tabuchi Y, Ono T, Makino T. Historical and pharmacological studies on rehmannia root processing-trends in usage and comparison of the immunostimulatory effects of its products with or without steam processing and pretreatment with liquor. J Ethnopharmacol. 2019;242:112059.

10. Chen FP, Chang CM, Hwang SJ, Chen YC, Chen FJ. Chinese herbal prescriptions for osteoarthritis in Taiwan: analysis of national health insurance dataset. BMC Complement Altern Med. 2014;14:91.

11. Jhun JY, Na HS, Shin JW, Jung KA, Seo HB, Ryu JY, Choi JW, Moon SJ, Park HJ, Oh SW, Cho ML, Min JK. Notoginseng Radix and Rehmanniae Radix Preparata extract combination (YH23537) reduces pain and cartilage degeneration in rats with monosodium iodoacetate-induced osteoarthritis. $\mathrm{J}$ Med Food. 2018;21:745-54.

12. Siu WS, Shum WT, Cheng W, Wong CW, Shiu HT, Ko CH, Leung PC, Lam CWK, Wong CK. Topical application of Chinese herbal medicine DAEP relieves the osteoarthritic knee pain in rats. Chin Med. 2019;14:55.

13. Gong G, Wang H, Kong X, Duan R, Dong TTX, Tsim KWK. Flavonoids are identified from the extract of Scutellariae Radix to suppress inflammatory-induced angiogenic responses in cultured RAW 264.7 macrophages. Sci Rep. 2018;8:17412. 
14. Gong G, Xie F, Zheng Y, Hu W, Qi B, He H, Dong TT. Tsim KW. The effect of. methanol extract from Saussurea involucrata in the lipopolysaccharide-stimulated inflammation in cultured RAW 264.7 cells. J Ethnopharmacol. 2020;251:112532.

15. Gong AG, Zhang LM, Lam CT, Xu ML, Wang HY, Lin HQ, Dong TT, Tsim KW. Polysaccharide of Danggui Buxue Tang, an ancient Chinese herbal decoction, induces expression of pro-inflammatory cytokines possibly via activation of NFKB signaling in cultured RAW 264.7 Cells. Phytother Res. 2017;31:274-83.

16. Geyer M, Schönfeld C. Novel insights into the pathogenesis of osteoarthritis. Curr Rheumatol Rev. 2018;14:98-107.

17. Ansari MY, Ahmad N, Haqqi TM. Oxidative stress and inflammation in osteoarthritis pathogenesis: role of polyphenols. Biomed Pharmacother. 2020;129:110452.

18. Chai LJ, Zhang Y, Zhang PY, Bi YN, Yuan XM, Li YH, Wang YY, Song L, Sun LK, Zhou K. The antiosteoporosis effects of Zhuanggu Guanjie Pill in vitro and in vivo. Biomed Res Int 2018; 9075318.

19. Dong TT, Zhao KJ, Gao QT, Ji ZN, Zhu TT, Li J, Duan R, Cheung AW, Tsim KW. Chemical and biological assessment of a Chinese herbal decoction containing Radix Astragali and Radix Angelicae Sinensis: determination of drug ratio in having optimized properties. J Agric Food Chem. 2006;54:2767-74.

20. Gong AG, Lau KM, Xu ML, Lin HQ, Dong TT, Zheng KY, Zhao KJ, Tsim KW. The estrogenic properties of Danggui Buxue Tang, a Chinese herbal decoction, are triggered predominantly by calycosin in MCF-7 cells. J Ethnopharmacol. 2016;189:81-9.

21. Chien SY, Tsai CH, Liu SC, Huang CC, Lin TH, Yang YZ, Tang CH. Noggin inhibits IL-1beta and BMP-2 expression, and attenuates cartilage degeneration and subchondral bone destruction in experimental osteoarthritis. Cells. 2020;9:927.

22. Fan L, He Y, Han J, Ybuan P, Guo X, Wang W. The osteoarthritis-associated gene PAPSS2 promotes differentiation and matrix formation in ATDC5 chondrogenic cells. Exp Ther Med. 2018;16:5190200.

23. Li Y, Mu W, Ren J, Wuermanbieke S, Wahafu T, Ji B, Ma H, Amat A, Zhang K, Cao L. Artesunate alleviates interleukin-1beta-induced inflammatory response and apoptosis by inhibiting the NFkappaB signaling pathway in chondrocyte-like ATDC5 cells, and delays the progression of osteoarthritis in a mouse model. Int J Mol Med. 2019;44:1541-51.

24. Kaptchuk TJ. The web that has no weaver: understanding Chinese medicine. McGraw-Hill. New York, 2nd.

25. Jiang M, Zhao S, Yang S, Lin X, He X, Wei X, Song Q, Li R, Fu C, Zhang J, Zhang Z. An "essential herbal medicine"-licorice: a review of phytochemicals and its effects in combination preparations. $J$ Ethnopharmacol. 2020;249:112439.

26. Yang HJ, Shen D, Xu HY, Lu P. A new strategy in drug design of Chinese medicine: theory, method and techniques. Chin J Integr Med. 2012;18:803-6. 
27. Su X, Yao Z, Li S, Sun H. Synergism of chinese herbal medicine: illustrated by Danshen compound. Evid Based Complement Alternat Med 2016; 7279361.

28. Zhang Y, Lyu C, Fong SYK, Wang Q, Li C, Ho NJ, Chan KS, Yan X, Zuo Z. Evaluation of potential herbdrug interactions between oseltamivir and commonly used anti-influenza Chinese medicinal herbs. $J$ Ethnopharmacol. 2019;243:112097.

29. Zhang JH, Li YP, Zhang BL. Evidence-based Chinese medicine: theory and practice. Zhongguo Zhong Yao Za Zhi. 2018;43:1-7.

30. Du CY, Choi RC, Zheng KY, Dong TT, Lau DT, Tsim KW. Yu Ping Feng San, an ancient Chinese herbal decoction containing Astragali Radix, Atractylodis Macrocephalae Rhizoma and Saposhnikoviae Radix, regulates the release of cytokines in murine macrophages. PLoS One. 2013;8:e78622.

31. Du CY, Choi RC, Dong TT, Lau DT, Tsim KW. Yu Ping Feng San, an ancient Chinese herbal decoction, regulates the expression of inducible nitric oxide synthase and cyclooxygenase- 2 and the activity of intestinal alkaline phosphatase in cultures. PLoS One. 2014;9:e100382.

32. Malemud CJ. Inhibition of MMPs and ADAM/ADAMTS. Biochem Pharmacol. 2019;165:33-40.

33. Quartana PJ, Finan PH, Page GG, Smith MT. Effects of insomnia disorder and knee osteoarthritis on resting and pain-evoked inflammatory markers. Brain Behav Immun. 2015;47:228-37.

34. Lieberthal J, Sambamurthy N, Scanzello CR. Inflammation in joint injury and post-traumatic osteoarthritis. Osteoarthritis Cartilage. 2015;23:1825-34.

35. Serafini M, Peluso I, Raguzzini A. Flavonoids as anti-inflammatory agents. Proc Nutr Soc. 2010;69:273-8.

36. Xiao S, Wang C, Yang Q, Xu H, Lu J, Xu K. Rea regulates microglial polarization and attenuates neuronal apoptosis via inhibition of the NF-KB and MAPK signalings for spinal cord injury repair. $J$ Cell Mol Med. 2021;25:1371-82.

37. Xie W, Du L. Diabetes is an inflammatory disease: evidence from traditional Chinese medicines. Diabetes Obes Metab. 2011;13:289-301.

38. Jin H, Wang L, Xu C, Li B, Luo Q, Wu J, Lv Y, Wang G, Dong J. Effects of Psoraleae Fructus and its major component psoralen on Th2 response in allergic asthma. Am J Chin Med. 2014;42:665-78.

\section{Figures}



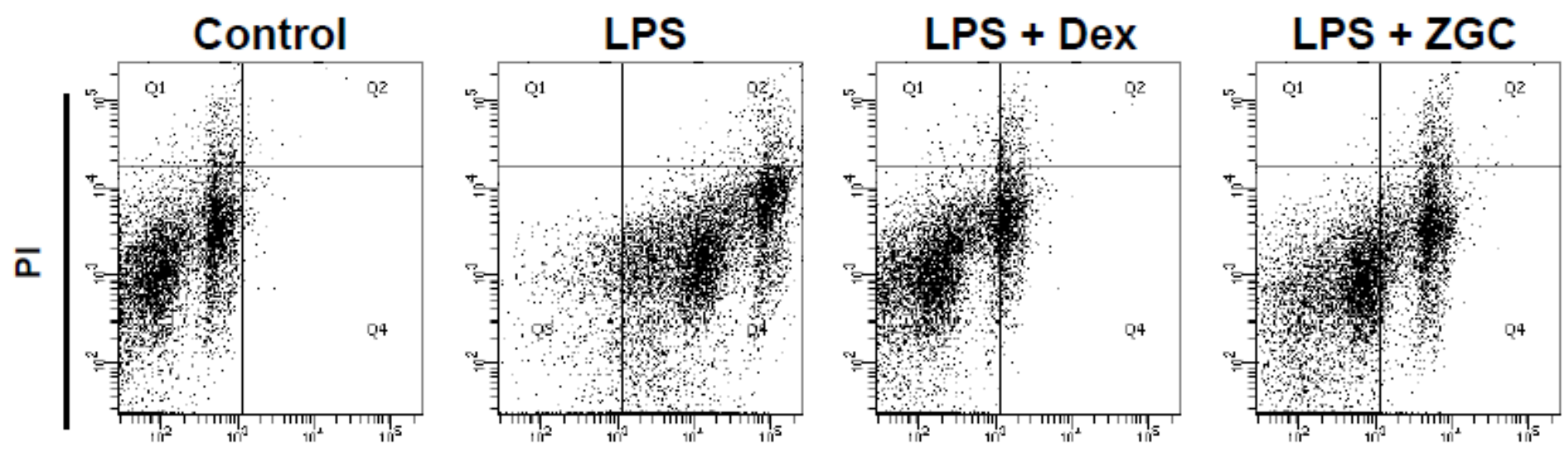

Annexin V FITC

Figure 1

ZGC mitigates cell apoptosis Cultured cells were treated with LPS $(1 \mu \mathrm{g} / \mathrm{mL})$ for 24 hours and then incubated with $0.25 \mathrm{mg} / \mathrm{mL}$ of ZGC for another 48 hours. Dex $(10 \mu \mathrm{M})$ acted as positive control. The dual parametric dot plots combining annexin V-FITC and PI fluorescence showed the viable cell population in the bottom left quadrant (Q3), the early apoptotic cells in the bottom right quadrant (Q4), and the late apoptotic cells in the top right quadrant (Q2).
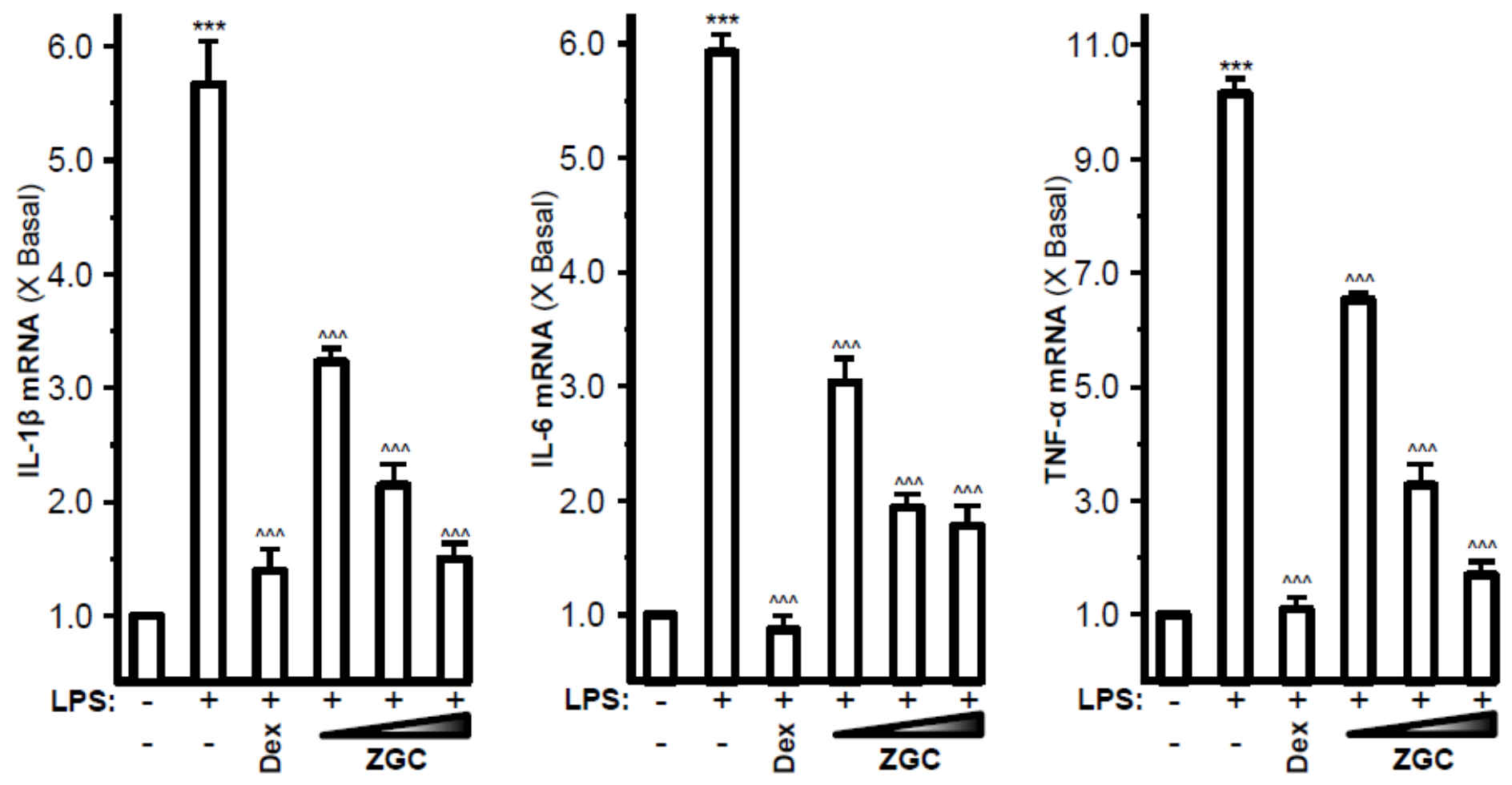

Figure 2 
ZGC attenuates mRNA levels of cytokine in cultured LPS pre-treatment chondrocyte-like cells. LPSinduced cultured chondrocyte-like cells were incubated with ZGC extracts at different concentrations $(0.125,0.25,0.5 \mathrm{mg} / \mathrm{mL})$ for 48 hours. The mRNA levels of IL-1 $\beta$, IL- 6 and TNF-a were measured by realtime PCR. GAPDH served as internal control. Dex $(10 \mu \mathrm{M})$ acted as positive control. Data are expressed as the fold of change to reference reading (blank control group) and in Mean $\pm S E M$, where $n=3$.

Statistically significant changes were clustered as highly significant $\left({ }^{\star \star \star}\right)$ and/or $\left({ }^{\wedge \wedge \wedge}\right)$ where $p<0.001$ as compared with control group and/or LPS-mimicking osteoarthritis model group, respectively.
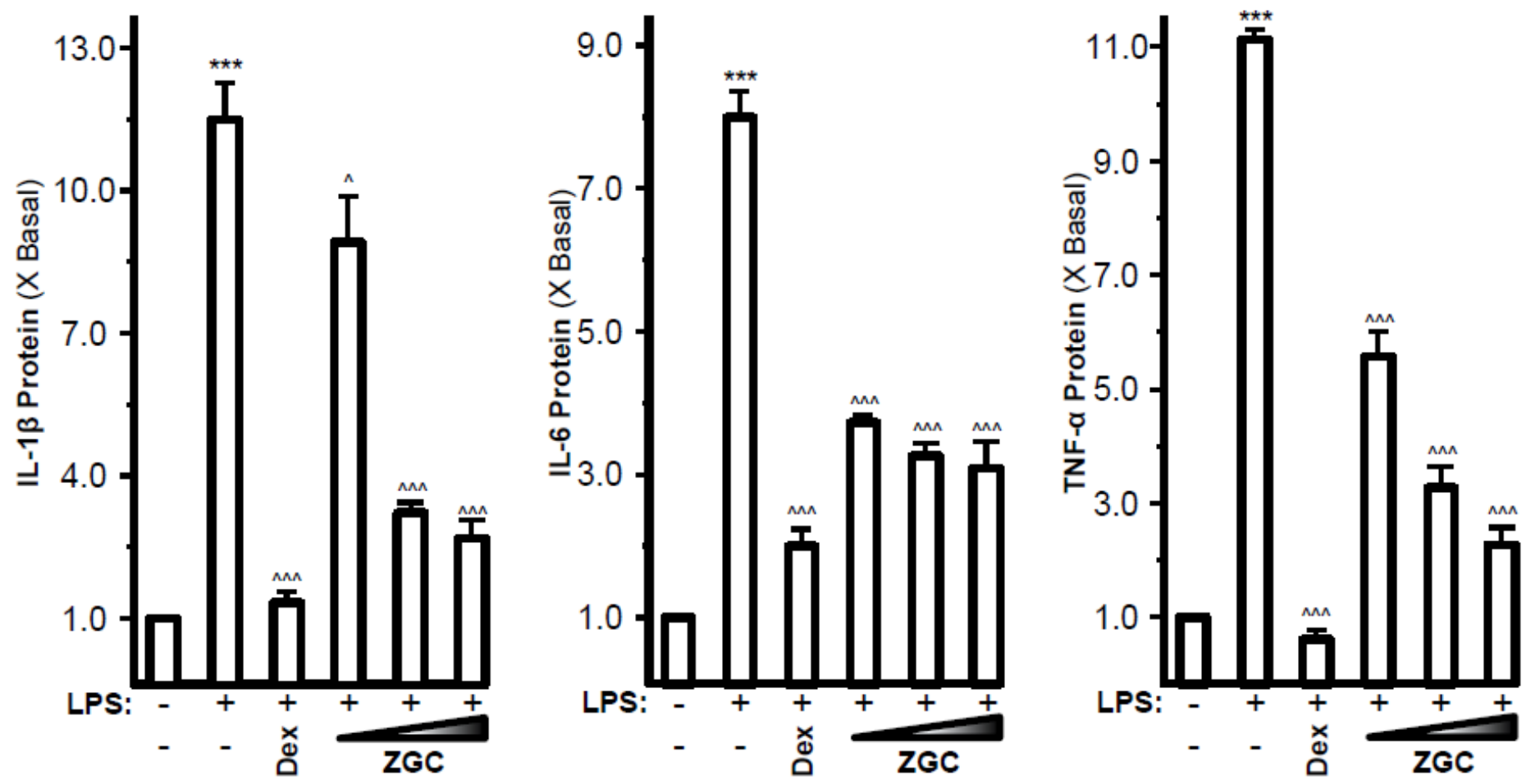

Figure 3

ZGC attenuates cytokine production contents in cultured LPS pre-treatment chondrocyte-like cells. LPSinduced cultured chondrocyte-like cells were incubated with ZGC extracts at different concentrations $(0.125,0.25,0.5 \mathrm{mg} / \mathrm{mL})$ for 48 hours. The cytokine release contents of IL-1 $\beta$, IL- 6 and TNF-a were measured by Milliplex ${ }^{\circledR}$ technology according to standard protocols. Here, Dex $(10 \mu \mathrm{M})$ was applied as positive control. Data are expressed as the fold of change to reference reading (blank control group) and in Mean $\pm S E M$, where $n=3$. Statistically significant changes were clustered as significant $\left({ }^{\wedge}\right)$ where $p<$ 0.05 as compared with LPS-mimicking osteoarthritis model group. Statistically significant changes were clustered as highly significant $(* \star \star)$ and/or $\left({ }^{\wedge \wedge \wedge}\right)$ where $p<0.001$ as compared with control group and/or osteoarthritis model group, respectively. 


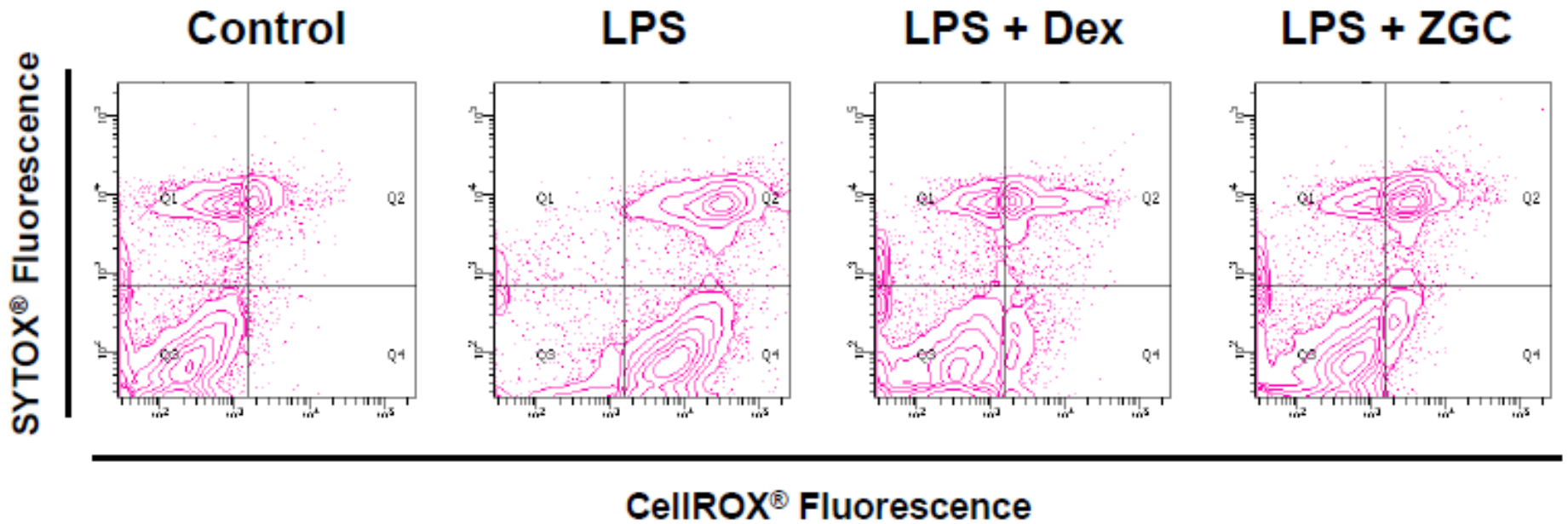

Figure 4

ZGC alleviates ROS formation in LPS pre-treated differentiated ATDC5 cells. Cultured differentiated ATDC5 cells were pre-treated with LPS $(1 \mu \mathrm{g} / \mathrm{mL})$ for 1 day then applied with $0.25 \mathrm{mg} / \mathrm{mL}$ of ZGC water extract or $10 \mu \mathrm{M}$ Dex for another 48 hours. Fluorimetric measurement by CellROX® detection kit and analyzed by Flowjo software. 

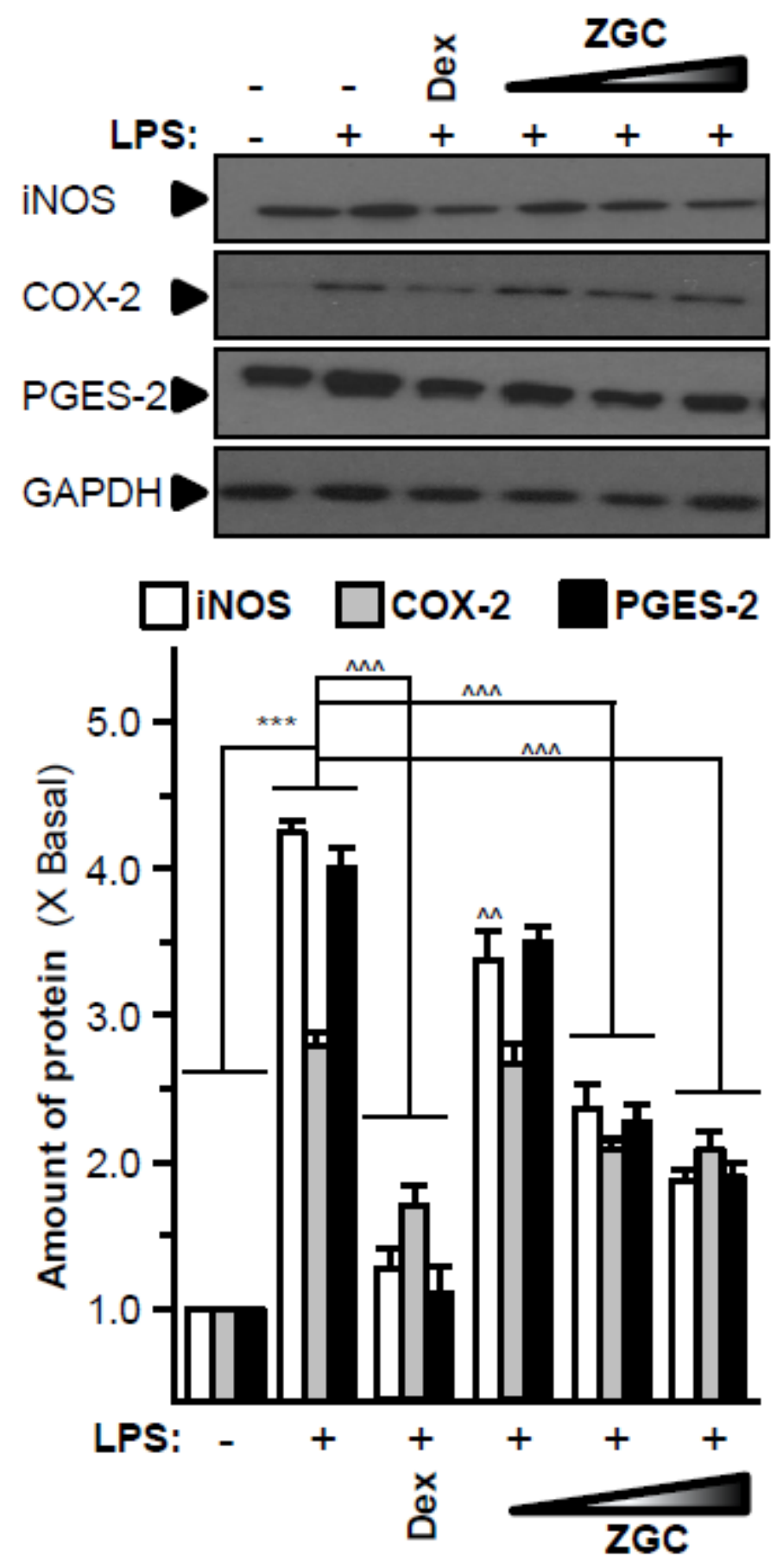

Figure 5

ZGC mitigates iNOS, COX-2 and PGES-2 translational levels in vitro. LPS-induced cultured chondrocytelike cells were incubated with ZGC extracts at different concentrations $(0.125,0.25,0.5 \mathrm{mg} / \mathrm{mL})$ for 48 hours. Total protein was collected and revealed by immunoblot analysis by specific antibodies. GAPDH served as an internal control. One $\mu \mathrm{g} / \mathrm{mL}$ of LPS was employed here as osteoarthritis model. Dex (10 $\mu \mathrm{M})$ acted as positive control. Data are expressed as the fold of change to reference reading (blank control group) and in Mean \pm SEM, where $n=3$. Statistically significant changes were clustered as significant 
$\left({ }^{\wedge \wedge}\right)$ where $p<0.01$ as compared with LPS model group, highly significant $\left({ }^{* \star *}\right)$ or $\left({ }^{\wedge \wedge}\right)$ where $p<0.001$ as compared with blank control group or model group, respectively.

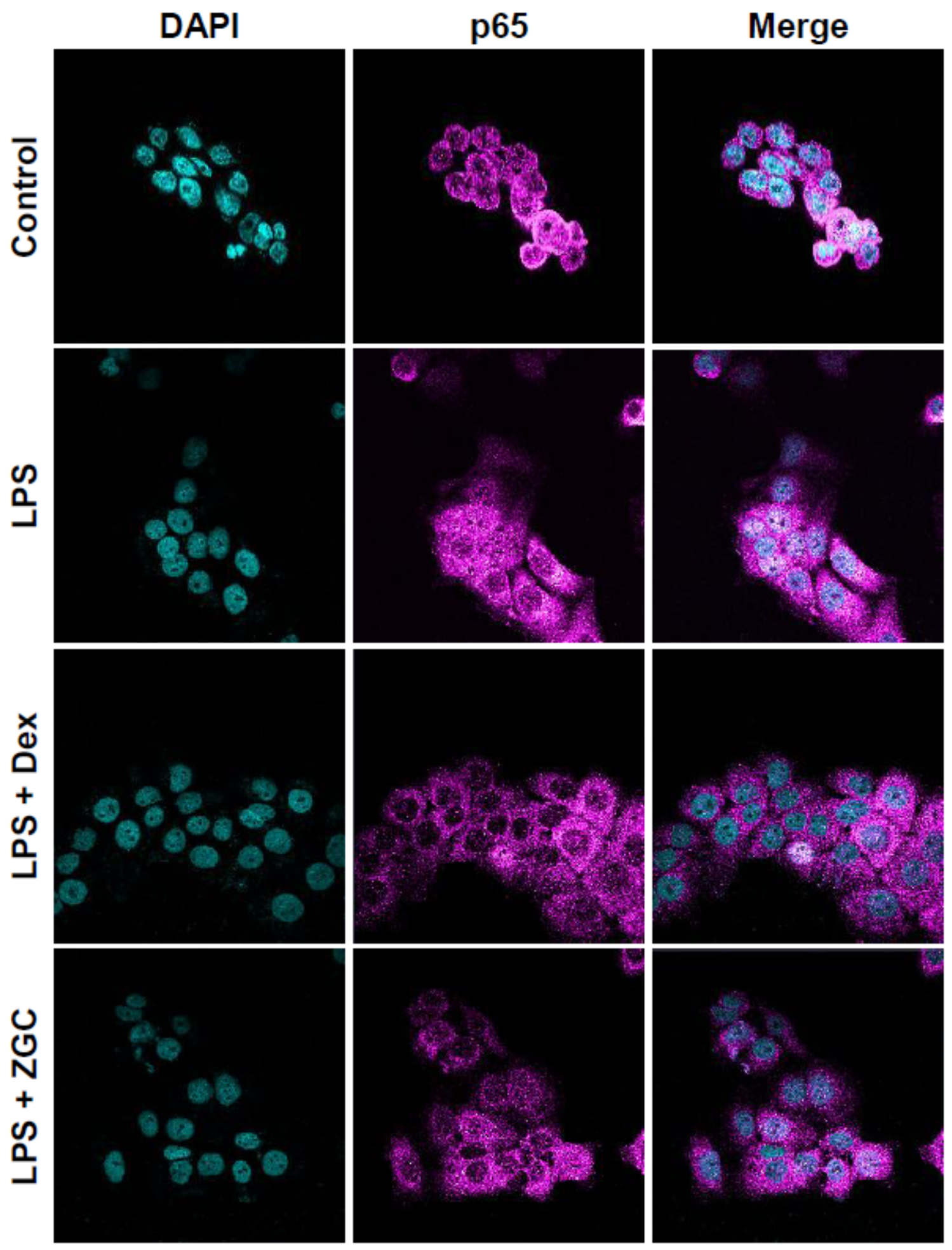

Figure 6

ZGC constricts NF-KB translocation in LPS pre-treatment chondrocyte-like cells. The NF-kB p65 translocation properties under the application of ZGC for 48 hours were detected in LPS pre-treated chondrocyte-like cells by confocal microscope. After applied with $0.25 \mathrm{mg} / \mathrm{mL}$ of ZGC extract for 48 
hours, p65 nuclear localization was revealed by confocal microscopy. Nuclei were stained by DAPI. LPS $(1 \mu \mathrm{g} / \mathrm{mL})$ mimicked the osteoarthritis status in vitro. Dex $(10 \mu \mathrm{M})$ acted as positive control. 